\title{
Teacher Transformation as a Basis for the Promotion of Self-Regulated Language Strategies
}

\author{
Meral Seker, Ayca Dincer \\ Cukurova University, Turkey
}

\begin{abstract}
The increasing interest in foreign language education for promoting self-regulated learning (SRL) needs special consideration at teachers' level. In order to equip higher education learners with self-regulated learning strategies, teachers need to adapt a support system where learners are provided autonomy and responsibility in their learning process. Since SRL is rather a complex process with multiple inter-related factors, learners need to be given systematic and continuous guidance by teachers. Considering the key role that teachers have in language teaching, the study attempts to identify foreign language teachers' opinions about the importance and the level of use of self-regulated language learning strategies in their classes while identifying the major impediments in its promotion. The qualitative data was gathered via semistructured interviews with twenty English instructors teaching at school of foreign languages at a state university. The results of the analyses revealed that promotion of SRL strategies remained at very low levels with limited number of methods applied. The findings highlight the need to incorporate methods of SRL instruction at both in-service and pre-service teacher education on the way to promote self-regulated autonomous language learners.
\end{abstract}

\section{Introduction}

SRL and its role in promoting autonomous lifelong learning have been receiving an increasing interest in educational research [1-2]. SRL refers to an active process where learners are capable of making necessary decisions and subsequently executing appropriate strategies throughout their learning. In higher education, promoting independent lifelong learners who can maintain and extend previously learned competencies in their professional life can be enhanced by incorporating SRL strategies into class instruction. Such implementations will require teachers in higher education to actively incorporate self-regulation instruction to formal education and assist learners with the ability to regulate their learning autonomously during their education and equip them with necessary skills to sustain life-long learning after completing formal education. However, fostering SRL among learners needs special consideration in planning and delivering teaching since it is rather a complex process where multiple inter-related factors play role. Among these factors, the impact of teachers' perceptions toward and implementation of SRL have been frequently mentioned as important determinants [2-3]. In order for teachers to promote SRL in higher education, they need to be aware of learners' prior knowledge and adapt their teaching and materials accordingly to assist them develop SRL strategies. As teachers need to reflect on their ideas and to be aware of their own teaching beliefs regarding SRL in order to effectively implement SRL into their teaching practices, any inquiry directed towards understanding these processes must entail teachers' personal contexts, their convictions, and their own personal questions. In this respect, the present study attempts to identify teachers' personal theories and attributions about self-regulated learning and its implementation in their teaching practices. In this respect, the present study seeks answers to the following research questions:

1) What are language teachers' opinions on the use of SRL strategy use?

2) How much time and effort do language teachers allocate to promote SRL strategies?

3) What are the methods and techniques utilized by teachers to promote SRL strategy use?

4) What are the reasons of teachers for not being able to promote SRL in their teaching?

5) What are teachers' suggestions to promote SRL more effectively?

\section{Literature Review}

As higher education in the global scale has significantly increased in student numbers [4-5], and as the dominant profile of new generation of students has moved toward non-traditional, ambitious to learn and technologically more advanced students [4], recent studies have been emphasizing the key role of self-regulated learning strategies for higher education [6-7]. A great number of studies address SRL strategies as effective tools for students to adjust and develop in higher education [8-9]. They have revealed that self-regulation has significant positive correlations with achievement in higher education since they enable students create systematic personal methods of learning to improve their performance and to adapt to changing contexts throughout their personal and professional life [3].

However, research in the field indicates that a large number of higher education students lack self- 
regulated learning skills [10-11]. To develop SRL strategies, students need systematic and continuous guidance in all levels of teaching and learning practices. These practices should encourage and assist students to set their learning goals, develop cognitive skills, metacognitive skills and affective skills to improve self-regulated learning, achieve skills for self-monitoring and self-evaluation [1]. Self-regulated strategies can be improved through guidance, modeling in an enabling environment including the physical setting, material resources, information communication technologies as a tool and social interaction and positive support.

\subsection{SRL in Foreign Language Learning}

As foreign language learning requires managing multiple factors, integrating SRL strategies to language instruction can assist learners to operate their learning [12]. Studies in the field of education have demonstrated that SRL enhances language learners' autonomy, their ability to manage tasks and other learning materials while increasing their resistance to unwarranted fears and social inhibitors and generating intrinsic motivation [13-14]. Rahimi and Katal [15] summarize the areas where effective implementation of SRL leads to language improvement:

\begin{abstract}
When chosen consciously, language learning strategies can act as a key to active, conscious, and purposeful self-regulated learning. ... The goal of strategy training is self-diagnosis, awareness of how to learn target language most efficiently, developing problem solving skills, experimenting familiar and unfamiliar learning strategies, decision making about how to approach a task, monitoring and self-evaluation, transferring successful learning strategies to new learning contexts, and enabling students to become more independent, autonomous, and lifelong learners (p.74).
\end{abstract}

Each component of SRL assists language learners in managing different language learning strategies. The use of cognitive strategies, for example, will guide learners to select, combine and coordinate necessary strategies and enhance the use of metacognitive strategies to organize, comprehend, analyze and evaluate their learning [16]. Metacognitive strategies, on the other hand, enhance comprehension of written tasks, facilitate information recall, help completion of new types of learning tasks and increase the quality and the speed of learners' cognitive engagement. Affective strategies help to increase enjoyment and satisfaction of learning; to praise achievements to generate motivation for next learning; to block negative emotions; to facilitate decision-making; and to promote learning by preparing to act on learning situations [14]. However, language learning occurs not only by applying knowledge and competences but it also consists of social aspects of learning. Social strategies, in this respect, encourage learners to interact with others; to ask for assistance or guidance; to learn from others; to discover different learning styles and act actively in social contexts [2].

\subsection{The Role of Teacher Perspectives in Promoting SRL}

In any given classroom setting, the teacher is one of the most important agents in the learning process. Decisions related to learning goals, task choice, class interaction procedures, or criteria for evaluation of student progress are made or finalized by the teacher. These decision-making processes are given in the light of teachers' perceptions [17]. A teacher, therefore, goes through a multidimensional decisionmaking process that involves determining the strategies students need to develop, identifying teaching approaches and methods to assist them develop necessary learning strategies, and choosing teaching materials and tasks suitable for their specific teaching context.

In order to equip higher education students with self-regulated learning strategies, teachers need to adapt a support system where students are provided autonomy and responsibility in their learning process and are scaffold especially during the initial period of gaining expertise. Providing such an enabling learning environment will require "... a new role for teachers which focuses on process-orientated teaching with students actively involved in the learning process, i.e. 'learn how to learn'; any interventions to promote self-regulated learning are likely to be long-term" (p. 15) [1]. Adapting a teaching style to guide and support students to develop awareness and capabilities for such strategies, teachers need to perceive their role as comprising the promotion of SRL. As teachers need to reflect on their ideas and to be aware of their own teaching beliefs regarding SRL strategies in order to effectively implement them into their teaching practices, any inquiry directed towards understanding these processes must entail teachers' personal contexts, their convictions, and their own personal questions $[1,17]$.

\section{Method}

The data for the study was gathered through semistructured interviews from 20 instructors teaching at a foreign language school at a state university. All teachers were female aged between 30 and 45 with teaching experience from 10 years to 20 years. 


\subsection{Data Collection Tool and Analysis}

The data for the study was gathered from the semi-structured interviews with the participating teachers. The interview questions were directed towards three specific purposes: (1) to identify teachers' opinions on learners' level of SRL strategy use; (2) to find out how much time and effort the teachers allocate to promote SRL strategies; (3) to determine the methods and techniques utilized by teachers to promote SRL strategy use; and (4) to determine reasons for not being able to promote SRL in their teaching. Each interview lasted between 20 and 30 minutes and was audio-recorded, transcribed, and analyzed adopting the grounded theory method [18]. The grounded method requires first eliciting participants' opinions, and then grouping the emergent themes to form categories based on the data collected.

\section{Results}

The participating teachers' responses were analyzed descriptively. Accordingly, all of the teachers stated that they believed that their students should know and apply SRL strategies. However, when the teachers were asked how much time and effort they spend to promote SRL strategies in their lessons, only few of them $(20 \%)$ stated that they often spent time to promote them. The majority indicated that they only sometimes spend time to introduce SRL (60\%) while $20 \%$ of them stated that they did not allocate any time for SRL instruction in their classes. The participants who stated to be allocating time for SRL instruction were asked to share the methods and techniques they used. Table 1 displays their responses.

Table 1. Methods and techniques used by teachers to promote SRL

\begin{tabular}{|l|l|c|}
\hline No & Methods and Techniques & Rate \\
\hline $\begin{array}{l}\text { Cognitive } \\
\text { Strategies }\end{array}$ & $\begin{array}{l}\text { Asking learners questions to increase } \\
\text { awareness of learning strategies }\end{array}$ & $10 \%$ \\
\hline \multirow{5}{*}{$\begin{array}{l}\text { Metacognitive } \\
\text { Strategies }\end{array}$} & $\begin{array}{l}\text { Explaining learners the importance } \\
\text { of setting learning goals }\end{array}$ & $30 \%$ \\
\cline { 2 - 3 } & Giving learners responsibility & $20 \%$ \\
\cline { 2 - 3 } & $\begin{array}{l}\text { Encouraging learners to handle } \\
\text { learning tasks }\end{array}$ & $15 \%$ \\
\cline { 2 - 3 } & $\begin{array}{l}\text { Explaining the steps to complete } \\
\text { learning tasks }\end{array}$ & $15 \%$ \\
\cline { 2 - 3 } & $\begin{array}{l}\text { Giving learners clues about } \\
\text { completing tasks }\end{array}$ & $15 \%$ \\
\cline { 2 - 3 } & $\begin{array}{l}\text { Giving learners time to reflect on } \\
\text { their learning progress }\end{array}$ & $15 \%$ \\
\cline { 2 - 3 } & $\begin{array}{l}\text { Encouraging learners to try new } \\
\text { learning styles }\end{array}$ & $5 \%$ \\
\hline
\end{tabular}

The results show that teachers who integrated SRL instruction to their classes mainly focused on metacognitive strategies. Their methods were directed toward setting goals, planning learning, and monitoring and evaluating learning. One of the teachers voiced the importance of setting goals as follows:

\section{Excerpt 1:}

I think a student can become an efficient learner once he or she knows what they need to learn at university. Then, they should be organizing and planning their learning accordingly. But, knowing what they want is the starting point.

Other metacognitive strategies such as maintaining concentration, obtaining necessary resources, implementing and monitoring plans were not mentioned. As for cognitive strategy instruction, only one method was stated and it was related to activating knowledge. Cognitive strategies such as conceptualizing, going beyond existing data, analyzing and synthesizing knowledge gained or processing information were not mentioned. The findings also reveal that affective and social dimensions of SRL strategies were not considered among the implemented methods. However, affective strategies such as identifying mood and anxiety levels and managing them, activating and maintaining motivation and supportive emotions are important parts of language learning. In addition, social strategies like learning despite communication gaps, interacting to learn, dealing with different socio-cultural contexts and identities, sharing learning outcomes, or asking for and giving feedback were not included in the methods teachers used to promote SRL.

The following responses emerged when participant teachers were asked about the reasons for lack of SRL implementation in their teaching practices.

Table 2. Teachers' Reasons for Lack of SRL Promotion

\begin{tabular}{|l|l|}
\hline Responses & Rate \\
\hline Our syllabus is overloaded & $55 \%$ \\
\hline Teachers do not know much about SRL strategies & $35 \%$ \\
\hline Learners are reluctant to learn and to try new strategies & $30 \%$ \\
\hline Learners already have their own learning strategies & $15 \%$ \\
\hline
\end{tabular}

The findings reveal that the majority of teachers attribute lack of SRL strategy instruction to overloaded teaching content $(55 \%)$. A relatively high number of teachers $(35 \%)$ indicated that teachers themselves did not have enough knowledge on SRL strategies. There were also responses related to learners' lack of motivation to learn about new learning strategies $(30 \%)$, which was attributed to having their own learning strategies by some teachers $(15 \%)$. As one teacher stated: 


\section{Excerpt 2}

Whenever I want to explain my students how to complete a task or how they can learn better, I notice that very few of them listen to me. They have their learning habits and they don't want to spend any time or effort to try out something new.

As the last question of the interview, teachers were asked to give some suggestions on the promotion of SRL strategies in language learning contexts. Table 3 presents their responses.

Table 3. Teachers' Suggestions for SRL Promotion

\begin{tabular}{|l|l|}
\hline Responses & Rate \\
\hline $\begin{array}{l}\text { Teachers should be given in-service training on } \\
\text { SRL strategy instruction }\end{array}$ & $35 \%$ \\
\hline $\begin{array}{l}\text { Various materials that promote SRL strategies can } \\
\text { be used }\end{array}$ & $30 \%$ \\
\hline $\begin{array}{l}\text { SRL instruction should be given as a selective } \\
\text { course }\end{array}$ & $30 \%$ \\
\hline $\begin{array}{l}\text { SRL instruction should be a compulsory part of the } \\
\text { curriculum }\end{array}$ & $15 \%$ \\
\hline $\begin{array}{l}\text { Learners can participate in a SRL introduction } \\
\text { program at the beginning of a term }\end{array}$ & $15 \%$ \\
\hline
\end{tabular}

According to the results, a high number of teachers indicated a need for in-service training on SRL strategy instruction for teachers (35\%). Using various materials to promote SRL implementation by learners was another frequent recommendation (30 $\%)$. However, evaluating the overall results reveal that training learners on SRL had a much higher frequency (60\% in total) than suggestions for teachers themselves. This finding indicates that the majority of the participant teachers felt the need for learners' improvement on SRL rather than teachers. The following excerpt reflects some of the teachers' opinions on this view:

\section{Excerpt 2}

We don't have any time to spend training students on strategies. Students need to acquire these skills before coming to universities. If they still don't have the necessary skills or strategies to study languages or to study at their departments, then there can be selective lessons to learn them.

Teachers also mentioned that it is easier for students to acquire SRL strategies as they already use many of them in their daily life. This view is exemplified in the following excerpt:

\section{Excerpt 3:}

Today every young adult, even teenagers or children, is capable of using the internet and searching the world. They spend hours in front of the computer and has access to everything. They are usually busy with many things at the same time. Playing a game while chatting with a friend; and posting comments on Facebook at the same time with the music playing in the background and singing along with it is typical for them. They can multitask and access information. But, they often don't know what they need to get at the university. Being aware of needs and planning to achieve learning goals are the features that differentiate between a successful and an ordinary university student.

\section{Discussion and Conclusion}

The present study aimed at finding language teachers' opinions on the use and promotion of SRL strategies in foreign language classes. The overall results revealed that although all of the participant teachers believed in the benefits of SRL in language learning, only few of them allocated time to promote the strategies. The teachers who integrated SRL instruction to their classes were found to be addressing only few of the metacognitive and cognitive strategies whereas affective and social strategies were not among the mentioned strategies. It was also found that the methods and techniques used for SRL promotion were relatively limited. Although they claimed to be implementing SRL strategies at varying degrees, they emphasized several impediments that hinder integrating SRL instruction to their teaching practices. Overloaded syllabus or learners' reluctance were among the significant obstacles mentioned by the participant teachers. Some of the teachers also indicated the need for teacher training as they did not believe they were equipped sufficiently to promote SRL strategy use. However, the majority of the teachers suggested that learners themselves should acquire or be guided on these strategies instead of teachers.

Higher education institutional policy and practice should be enabling, in that they should reflect the need for opportunities to model and practice selfregulated learning for both students and teaching staff in order to address misconceptions and misunderstanding, demonstrate value and allow the development of appropriate skill sets for selfregulation. However, the results of the qualitative analyses in the present study revealed that although teachers claimed to be aware of the importance of SRL promotion in higher education, their implementations indicated low significance attributed to it.

The results of the study are limited in terms of the number of participants. Thus, it would be misleading to generalize the findings to a larger context. However, the findings are meant to point out 
to the need to consider incorporating methods of SRL instruction both at in-service and pre-service teacher education on the way to promote lifelong self-regulated higher education learners. The findings are meant to serve the preliminary ground for further studies that focus on teacher transformation as a basilar for SRL promotion by exploring and articulating personal beliefs of teachers.

\section{References}

[1] H. Cassidy, Skills, Tasks, and Occupational Choice, Unpublished manuscript, Department of Economics, The University of Western Ontario, 2012.

[2] R. L. Oxford, Teaching and Researching Language Learning Strategies, Harlow, UK: Pearson Longman, 2011.

[3] B. J. Zimmerman and D. H. Schunk, Reflections on Theories of Self-Regulated Learning and Academic Achievement, Self-Regulated Learning and Academic Achievement: Theoretical Perspectives, 2, 2001, pp. 289-307.

[4] T. D. Snyder and S. A. Dillow,Digest of Education Statistics 2011, National Center for Education Statistics, 2012.

[5] C. E. Kasworm, Adult Learners in a Research University: Negotiating Undergraduate Student Identity, Adult Education Quarterly, 60(2), 2010, pp. 143-160.

[6] M. D. Coomes and R. DeBard, A Generational Approach to Understanding Students, New Directions for Student Services, 106, 2004, pp. 5-16.

[7] L. J. Sax, S. K. Gilmartin, and A. N. Bryant, Assessing Response Rates and Nonresponse Bias in Web and Paper Surveys, Research in Higher Education, 44(4), 2003, pp. 409-432.

[8] J. D. Vermunt, Relations between Student Learning Patterns and Personal and Contextual Factors and Academic Performance, Higher Education, 49.3, 2005, pp. 205-234.

[9] A. M. Kosnin, Self-Regulated Learning and Academic Achievement in Malaysian Undergraduates, International Education Journal, 8(1), 2007, pp. 221-228.

[10] P, Virtanen and A. Nevgi, Disciplinary and Gender Differences among Higher Education Students in Self-Regulated Learning Strategies, Educational Psychology, 30(3), 2010, pp. 323-347.

[11] P. H. Winne and D. Jamieson-Noel, Self-Regulating Studying by Objectives for Learning: Students' Reports Compared to a Model, Contemporary Educational Psychology, 28(3), 2003, pp. 259-276.
[12] S. Shirkhani and F.Ghaemi. Barriers to SelfRegulation of Language Learning: Drawing on Bandura's Ideas, Procedia-Social and Behavioral Sciences, 29, 2011, pp. 107-110.

[13] Hergenhahn, B. R., and M. H. Olson. "Albert Bandura." An introduction to theories of learning (2005): 335-370.

[14] J. Bown and C. J. White, Affect in a Self-Regulatory Framework for Language Learning, System, 38(3), 2010, pp. 432-443.

[15] M. Rahimi and M. Katal, Metacognitive Strategies Awareness and Success in Learning English as a Foreign Language: An Overview, Procedia-Social and Behavioral Sciences, 31, 2012, pp. 73-81.

[16] M. Boekaerts, Self-Regulated Learning: A New Concept Embraced by Researchers, Policy Makers, Educators, Teachers, and Students, Learning and instruction, 7(2), 1997, pp. 161-186.

[17] O. Dickhauser, A Fresh Look: Testing the Internal/External Frame of Reference Model with FrameSpecific Academic Self-Concepts, Educational Research, 47(3), 2005, pp. 279-290.

[18] Stern, P.N., Grounded Theory Methodology: Its Uses and Processes. In B.G. Glaser (Ed.), Grounded Theory (pp.29-39), Mill Valley, CA: Sociology Press, 1995. 